\title{
An Improved Data Envelopment Analysis (DEA) Model to Measure China's Energy Efficiency
}

\author{
Liu Xiaqing ${ }^{1,2}$ \\ 1. Department of College English \\ Shandong Institute of Business and Technology \\ Yantai, P.R. China \\ 2. College of Economics and Management \\ Nanjing University of Aeronautics and Astronautics \\ Nanjing, P.R. China \\ e-mail: liuxiaqing111@163.com
}

\author{
Liu Lusi \\ School of Construction \\ Changan University \\ Xian, P. R. China \\ e-mail: roseliu6699@sina.com
}

\author{
Liu Xiao* \\ College of Economics and Management \\ Nanjing University of Aeronautics and Astronautics \\ Nanjing, P.R. China \\ e-mail: 332853225@qq.com \\ Liu Guixian ${ }^{1,2}$ \\ 1. School of Mathematics and Information Science \\ Henan Polytechnic University \\ Jiaozuo, P.R. China \\ 2. College of Economics and Management \\ Nanjing University of Aeronautics and Astronautics \\ Nanjing, P.R. China \\ e-mail: 578412118@qq.com \\ * Corresponding Author
}

\begin{abstract}
As the largest energy consumer, China is facing increasingly great pressure to guarantee energy supply and energy security, which puts higher demand for measuring and improving energy efficiency. DEA model has become a widely accepted method in measuring energy efficiency at the macro-economy level. Considering the maximum of desirable outputs, this paper develops a new DEA model based on super-efficiency evaluation. In view of the significant relationship between DEA efficiency and the Pareto solution, the effectiveness of the new DEA model and Pareto Optimality are analyzed. In addition, the new DEA model is utilized to study the development of China's energy efficiency of 21 years period from 1991 to 2011. The results show that China's energy efficiency has experienced such a trend as "down - rise - stationary wave -rise". Compared with the two classical models, the results are much more consistent with the real change trend, which indicates that the accuracy of the new DEA model is improved. The analysis of the influence factors by the Tobit model shows that the rising of energy price and technology progress can increase the efficiency. Finally, based on the research results, this paper gives some policy recommendations on increasing China's energy efficiency.
\end{abstract}

Keywords- DEA; Undesirable Outputs; Super-efficiency; TFEE (total factor energy efficiency); Tobit

\section{INTRODUCTION}

China's economy has grown rapidly in the past three decades, which results in severe environmental pollution and an acute shortage of energy supply. According to the Statistical Review of World Energy 2012, China has replaced the US as the largest energy consumer, contributing to $20.3 \%$ of global energy consumption. There is a great practical significance to study the energy and environment efficiency.

The DEA model firstly introduced by Charnes [1] is an effective non-parametric mathematical optimization technique for measuring the relative efficiency of a group of peer decision making units (DMUs) with multiple inputs and multiple outputs. Up to now, the DEA method has been widely used to study energy and environment problems [2-6]. For example, Bian and Yang proposed several DEA models to measure resource and environmental efficiency simultaneously [7-8]. M. Khodabakhshi [9] addressed super-efficiency issues based on improved outputs. Hu and Wang proposed a total factor energy efficiency (TFEE) evaluation method using DEA and measured the energy efficiency of 29 regions in China [10] Ma et al. used DEA model calculating the TFFE of Jiangsu Province during the period of 1995-2008 [11]. Wang and Yu utilized an improved DEA model to measure the energy and environmental efficiency of 29 administrative regions of China from 2000 to 2008 [12].

Based on the above analyses, the main purpose of this study is to develop an improved DEA model. Our extensions to the existing studies include the following item. (i) The undesirable outputs are incorporated into energy efficiency estimation. (ii) The new model uses total 
factor energy efficiency indicators based on super efficiency DEA model. (iii) The newly built DEA model will optimize the weight of each unit's inputs and outputs so as to control more desirable outputs and less undesirable outputs. (iv) Few articles analyze the link between DEA efficiency and the Pareto solution.

\section{METHODOLOGY}

The DEA method, as a non-parametric mathematical programming approach, is used to evaluate a set of comparable DMUs. We briefly describe the DEA model as following.

The DEA method, as a non-parametric mathematical programming approach, is used to evaluate a set of comparable DMUs. We briefly describe the DEA model as following.

Suppose there are $\mathrm{n}$ DMUs to be evaluated, which are denoted by $D M U_{j}(j=1,2, \cdots n)$. Each DMU has $k$ inputs, $m$ desirable outputs and $S$ undesirable outputs. Assume the corresponding data of the $D M U_{j 0}\left(D M U_{0}\right.$ for abbreviation) are denoted as $\left(X_{0}, Y_{0}, Z_{0}\right)$. The CCR $[1,3]$ model is presented as follows:

$$
\begin{aligned}
& \max \mu^{T} Y_{0} \\
& \text { s.t. }\left\{\begin{array}{l}
\varpi^{T} X_{j}-\mu^{T} Y_{j} \geq 0, j=1, \cdots, n \\
\varpi^{T} X_{0}=1 \\
\varpi \geq 0, \quad \mu \geq 0
\end{array}\right.
\end{aligned}
$$

Where, $X$ is the input vector, $Y$ is the output vector, $\varpi$ is the weight given to output vector, and $\mu$ is the weight given to input vector.

The efficiency calculated by model (1) is a kind of radial efficiency which has weak discriminating power in evaluating the energy efficiency. This paper improves the $C C R$ model, which is shown as follows.

$$
\begin{aligned}
& \max \mu^{T} Y_{0} \\
& \text { s.t. }\left\{\begin{array}{l}
\varpi^{T} X_{j}+\gamma^{T} Z_{j}-\mu^{T} Y_{j} \geq 0, j=1, \cdots, n \text { and } j \neq j_{0} \\
\varpi^{T} X_{0}+\gamma^{T} Z_{0}=1 \\
\gamma^{T} e-\mu^{T} \hat{e} \leq 0 \\
\varpi \geq 0, \quad \gamma \geq 0, \quad \mu \geq 0
\end{array}\right.
\end{aligned}
$$

The dual of the model (2) is:

$$
\begin{aligned}
& \min \theta
\end{aligned}
$$

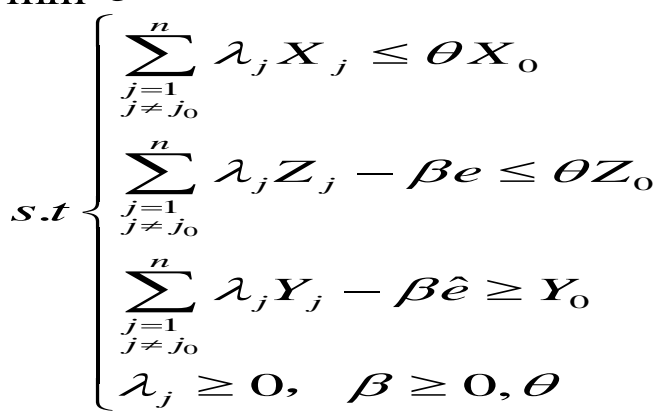

Where, $\gamma$ is weight given to undesirable output vector, $Z$ represents the undesirable output vector, $\hat{e}=(1, \ldots, 1)^{T} \in R^{m}, e=(1, \cdots, 1)^{T} \in R^{s}$

$\boldsymbol{\theta}$ is the energy and environmental efficiency index. If the index is lager, then the corresponding DMU performs better at the aspects of energy saving, pollutant emission reduction and the outputs controlling.

The differences between model (1) and model (2) lie in the constraint conditions, and the model (2) has some practical significances. Firstly, the model (2) considers both desirable and undesirable outputs brought by energy and related elements. Secondly, based on super efficiency DEA model, the new model can study total factor energy efficiency indicators. Furthermore, the newly built DEA model can optimize the weight of each unit's inputs and outputs so as to control the produce of outputs. To do so, one constraint condition $\gamma^{T} e-\mu^{T} \hat{e} \leq 0$ is added into the new model.

Definition 1. For each $\left(\mu^{*}, \varpi^{*}, \gamma^{*}\right) \in P$, if there exists $\mu^{*}, \varpi^{*}, \gamma^{*}$ with $\mu^{*} \geq 0, \quad \varpi^{*} \geq 0, \quad \gamma^{*} \geq 0$ and $\mu^{* T} Y_{0} \geq 1$, then $D M U_{0}$ is called weak DEA efficient.

Definition 2. For each $\left(\mu^{*}, \varpi^{*}, \gamma^{*}\right) \in P$ if there exists $\mu^{*}, \varpi^{*}, \gamma^{*}$ with $\mu^{*}>0, \quad \varpi^{*}>0, \quad \gamma^{*}>0$ and $\mu^{* T} Y_{0} \geq 1$, then $D M U_{0}$ is called $D E A$ efficient.

Definition 3. Assume the optimal solution $\lambda_{j}^{*}, \beta^{*}, \theta^{*}$, let $X=\sum_{\substack{j=1 \\ j \neq j_{0}}}^{n} \lambda_{j}^{*} X_{j}$, $Y=\sum_{\substack{j=1 \\ j \neq j_{0}}}^{n} \lambda_{j}^{*} Z_{j}-\beta^{*} e, Z=\sum_{\substack{j=1 \\ j \neq j_{0}}}^{n} \lambda_{j}^{*} Z_{j}-\beta^{*} e$, then $(X, Y, Z)$ is called the projection of $D M U_{0}$ in the efficient frontier.

In Eq.(3), the optimal value $\boldsymbol{\theta}^{*}$ is named as TFEE value. The higher $\theta^{*}$ is, the better the efficiency of the DMUs; vice versa. If $\theta^{*} \geq 1$, then the $\mathrm{DMU}_{*}$ is on the production frontier. Now we will introduce the following theorems, which are very important for the research in the real production.

Theorem 1. The linear programming (2) and (3) have the feasible solution.

Theorem 2. If $\left(X_{0}, Y_{0}, Z_{0}\right)$ is the Pareto solution, then it means $D M U_{0}$ gets $D E A$ efficiency. 


\section{DATE DESCRIPTION}

The research period in this paper starts from 1991 and ends in 2011. The annual data of fixed asset, labor force and energy consumption are used as inputs, while we use gross domestic product (GDP) as desirable output, and carbon dioxide $\left(\mathrm{CO}_{2}\right)$ and sulfur dioxide $\left(\mathrm{SO}_{2}\right)$ emissions as two undesirable outputs. Input and output variables are defined as follows: (i) The fixed asset and GDP data, collected from the China Statistical Yearbook (CSY), are measured in billion Yuan in constant 1991 price, [13]. (ii) Annual energy consumption is used to represent the invested energy, and its data are mainly from the corresponding years of the China Energy Statistical Yearbook (CESY) [14]. (iii) Labor force data which select the average value of employment at the beginning and the end of years are from the China Statistical Yearbook, and the unit is million. (iv) The data of $\mathrm{SO}_{2}$ emission are obtained from the China Statistical Yearbook on Environment from 1991-2011. (iiv) The $\mathrm{CO}_{2}$ emissions are mainly from fossil energy consumption, so following Liu et.al, we estimate the data on $\mathrm{CO}_{2}$ from the amounts fossil energy[17].

Table 1 illustrates the summary statistics of input and output variables. Obviously, on average, the investment of fixed asset, number of laborers, energy consumption, both GDP and $\mathrm{CO} 2$ emissions for the 21 DMUs of China increased, while only the SO2 emissions have a slight fluctuation. Wherein, $\mathrm{K}$ is the fixed asset; $\mathrm{L}$ is the supply of labor; $\mathrm{CO}_{2}$ is the emission of $\mathrm{CO}_{2}, \mathrm{SO}_{2}$ is the emission of $\mathrm{SO}_{2}$; GDP is gross domestic product; and, $E$ is total energy consumption in aggregated level or industrial energy consumption in disaggregated level.

TABLE I. SUMMARY STATISTICS OF INPUTS AND OUTPUTS

\begin{tabular}{|c|c|c|c|c|c|c|}
\hline \multirow[b]{2}{*}{ Year.. } & \multicolumn{3}{|c|}{ Inputs Factors. } & \multirow{2}{*}{$\begin{array}{c}\text { Desirable outputs } \\
\text { GDP } \\
\text { (billion) }\end{array}$} & \multicolumn{2}{|c|}{ Undesirable outputs. } \\
\hline & $\begin{array}{c}E .1 \\
\text { (Mtce) }\end{array}$ & $\begin{array}{c}K . \\
\text { (billion) }\end{array}$ & $\underset{\text { (million) }}{L .1}$ & & $\begin{array}{l}\mathrm{CO}_{2 \cdot 1} \\
(\mathrm{Mt}) .\end{array}$ & $\begin{array}{l}\mathrm{SO}_{2 \cdot 1} \\
(\mathrm{Mt}) .\end{array}$ \\
\hline 1991.2 & 1037.83 & 559.45. & 65491. & 2178.16 & 2369.25 & 16.21 .1 \\
\hline 1992. & 1091.70 & 700.79. & 66152. & 2484.52 .1 & 2449.16 & 16.22. \\
\hline 1993.7 & 1159.93. & 895.98., & 66808., & 2824.10 & 2626.64 & 17.95. \\
\hline 1994. & 1227.37. & 1057.91. & 67455. & $3194.27 .$, & 2831.55. & 18.25. \\
\hline 1995. & 1311.76 & 1173.46 & 68065. & 3492.41. & 2861.68. & 13.96. \\
\hline 1996. & 1351.92. & 1291.63 & 68950. & 3848.37. & 2893.38. & 13.97. \\
\hline 1997. & 1359.09. & 1382.55 & 69820. & 4218.87. & 3081.74 & 23.46. \\
\hline 1998. & 1361.84 & 1578.12 & 70637. & 4527.37 .1 & 2967.26 & 20.90 \\
\hline 1999. & 1405.69. & 1665.07. & 71934. & 4887.05 .1 & 2885.72. & 18.58. \\
\hline 2000. & 1455.31. & 1815.65. & 72085 & 5305.11. & 2849.75 & 19.95 \\
\hline 2001. & 1504.06. & 2044.70. & 73025. & 5732.45. & 2969.58. & $19.48 .$. \\
\hline 2002.7 & 1594.31 & 2384.86 & 73740. & 6279.67. & 3464.84. & 19.27. \\
\hline 2003.1 & 1837.92. & 2981.04 & 74432. & 6937.53. & 4069.24 & 21.59. \\
\hline 2004 & 2134.56 & 3581.17. & 75200. & 7664.62. & 5089.78. & 22.55. \\
\hline 2005. & 2359.97. & 4440.90 & 75825. & 8493.16 & 5512.70. & 25.49. \\
\hline 2006. & 2586.76 & 5421.30 & 76400 & 9620.33. & 5817.14 & 25.89. \\
\hline 2007.2 & 2805.08 & 6514.42. & 75321. & 11028.97. & 6184.10 & 24.68. \\
\hline 2008. & 2914.48 & 7527.37. & 77046.1 & 12140.07 & 6721.43. & 23.21. \\
\hline 2009. & 3066.47. & 10022.26 & 77510. & 13152.87. & 7204.89. & 22.14 \\
\hline 2010. & 3249.39 & 10842.83 & 78388. & 14488.29. & 8320.96 & 22.68. \\
\hline 2011. & 3480.02. & $12588.31 .$. & 78579. & $15878.58 . \mathrm{r}$ & $8955.51 .$. & 22.18. \\
\hline
\end{tabular}


consumption keeps increasing gradually which indicates that the excessive energy consumption has already restricted the economic development in China. In other words, China will have to improve the energy efficiency and continue to rein the rapid growth of sectors with high energy consumption.

\section{B. Total Factor Energy Efficiency Analysis}

With the large amount of energy consumption, environmental problem, especially "climate change" has become the focus of the world since the UN Conference on Environmental and Development held in 1992. In 2011, the emission of $\mathrm{CO}_{2}$ had already reached 8955.1 million tons, which contributes that China becomes the world's largest $\mathrm{CO}_{2}$ emitter. Thus, energy shortage and environmental pollution have become the bottleneck of China's sustainable development. From this aspect, improvements in energy efficiency are regarded as a key mechanism for reducing energy dependence and meeting sustainability and security of supply goals. Different from $\mathrm{CCR}, \mathrm{BCC}$ and some traditional measures which assume the proportional reduction (enlargement) of input (output) vectors, the new model does have some better merits which have been proved in section 2. This part, China's energy efficiency values are calculated in 3 different models (Table 2). The 1991-2011 trends of China energy efficiency are drawn respectively in 3 different models as shown in Fig.3.

TABLE II. TOTAL FACTOR OF ENERGY EFFICIENCY IN DIFFERENT MODELS

\begin{tabular}{|c|c|c|c|c|c|c|c|c|}
\hline \multirow{2}{*}{ DMU } & \multicolumn{2}{|c|}{ CCR-DEA } & \multicolumn{2}{|c|}{ BCC-DEA } & \multicolumn{4}{|c|}{ NEW-DEA } \\
\hline & TFEE & Rank & TFEE & Rank & TFEE & Rank & PTE & SE \\
\hline 1991 & 1.000 & 1 & 1.000 & 1 & 1.098 & 1 & 1.025 & 1.071 \\
\hline 1992 & 0.988 & 15 & 0.975 & 14 & 0.983 & 15 & 0.999 & 0.984 \\
\hline 1993 & 0.938 & 20 & 0.983 & 13 & 0.938 & 20 & 0.997 & 0.941 \\
\hline 1994 & 0.937 & 21 & 0.993 & 12 & 0.937 & 21 & 0.999 & 0.938 \\
\hline 1995 & 0.981 & 16 & 0.983 & 17 & 0.946 & 19 & 0.999 & 0.946 \\
\hline 1996 & 1.000 & 1 & 0.998 & 10 & 0.964 & 17 & 0.999 & 0.965 \\
\hline 1997 & 0.998 & 12 & 1.000 & 1 & 0.998 & 10 & 1.000 & 0.998 \\
\hline 1998 & 0.963 & 19 & 0.994 & 11 & 0.963 & 18 & 0.995 & 0.968 \\
\hline 1999 & 0.999 & 10 & 0.951 & 21 & 0.991 & 14 & 0.995 & 0.997 \\
\hline 2000 & 1.000 & 1 & 0.964 & 16 & 1.022 & 6 & 1.023 & 0.999 \\
\hline 2001 & 1.000 & 1 & 0.967 & 15 & 1.031 & 3 & 1.038 & 0.993 \\
\hline 2002 & 1.000 & 1 & 0.955 & 18 & 1.023 & 5 & 1.037 & 0.986 \\
\hline 2003 & 0.993 & 14 & 0.952 & 20 & 0.994 & 13 & 0.996 & 0.997 \\
\hline 2004 & 0.995 & 13 & 1.000 & 1 & 0.996 & 11 & 0.997 & 0.999 \\
\hline 2005 & 0.975 & 18 & 1.000 & 1 & 0.977 & 16 & 0.988 & 0.989 \\
\hline 2006 & 0.977 & 17 & 1.000 & 1 & 1.004 & 7 & 1.009 & 0.995 \\
\hline 2007 & 1.000 & 1 & 1.000 & 1 & 1.002 & 8 & 1.004 & 0.998 \\
\hline 2008 & 1.000 & 1 & 1.000 & 1 & 1.025 & 4 & 1.050 & 0.976 \\
\hline 2009 & 1.000 & 1 & 0.953 & 19 & 0.996 & 12 & 0.996 & 1.000 \\
\hline 2010 & 0.999 & 10 & 1.000 & 1 & 1.000 & 9 & 1.000 & 1.000 \\
\hline 2011 & 1.000 & 1 & 1.000 & 1 & 1.093 & 2 & 1.023 & 1.069 \\
\hline
\end{tabular}

Note: (1) Arranged according to the data processing results of lingo 9.0. (2) TFEE = PTE (puretechnical efficiency) $\times$ SE (scale efficiency).

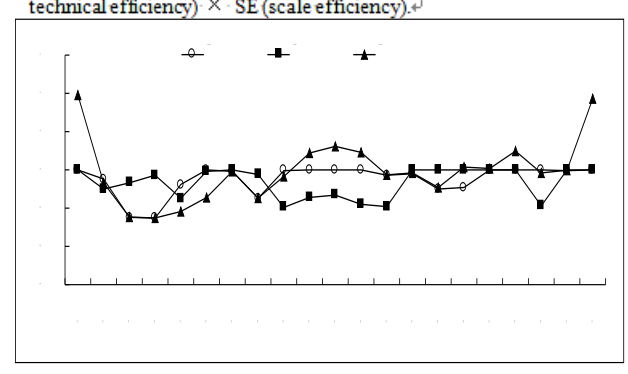

Figure 3. The efficiency value of different model
Table 2 and Fig. 3 illustrate the total factor energy efficiency of China from 1991 to 2011, as is shown below. (i) Only 1991, 2000-2002, 2006-2008, 2010 and 2011, 9 out of 21 reach the DEA efficiency under the new model. (ii) The results of new model show that 1991 gains the supreme efficiency score at 1.098, whereas, the year of 1994 gets the worst result with the efficiency value 0.937 . (iii) The performance of 1993-1998 is proved to be the worst. None of the year in this period reaches the DEA efficiency and, except 1997, the rest 5 years are ranked lowest through all the DMUs. (iv) On the whole, 8 out of 9 DMUs with DEA efficiencies are in the period of 20002011, which means policies had been taken to make inputs and outputs further optimized, thus, which in turn improves the TFEE in the latest years. As to the relatively low value in 2009 , the main reason may be that the rapidly economic growth and the process of urbanization which results in the massive investment of infrastructure. (v) From Figure 3, it is obvious to identify that China's energy efficiency has experienced such a trend like "down - rise stationary wave - rise". This kind of characteristic is consistent with Shi Dan's and Wang Weiqun's researches. Indeed, the results of new model have the same trend with the original CCR and BCC model, which means that the new model is basically consistent with the fact. What's more, the new calculated efficiency scores can also highlight the improved advantage at 3 empirical aspects as follows.

Firstly, DMUs with DEA efficiencies and inefficiencies can be distinguished by both CCR and BCC models, and the efficiency values can also be calculated. However, the key problem is that they can't rank the DMUs from the aspect of DEA efficiency. For example, the values of 1991, 1996, 2001, 2002, 2007, 2008, 2011 are all 1 by both CCR and BCC model. Thus, it is impossible to figure out which year is the best of all the DMUs. Meanwhile, the new model can have a further evaluation on the DMUs with DEA efficiencies and give completed index rankings (as shown in Table 2). The results show that there are 4 units, 1991, 2007, 2008 and 2011 reaching DEA efficiency examination through all three models. The new model is the only one indicating that energy efficiency value in 1991 is the highest, followed by 2011, 2008 and 2007. So the new model can help make a better reaction at the aspect of DMU's effective degree.

Secondly, the consideration of environmental factor is very important and significant, because in the real production process, people can't avoid the undesirable outputs such as the emission of $\mathrm{CO}_{2}$ and $\mathrm{SO}_{2}$. Neither CCR nor BCC model can take undesirable outputs into consideration, results in remarkable difference between estimation and realistic results. Take 1995 as an example, under the circumstance of a steady growth at the desired output, the emission of $\mathrm{SO}_{2}$ decreased by $23.6 \%$, as shown in Fig. 4, due to the environmental factors that favorable conditions are improved. So the efficiency value of new model with consideration of the undesirable outputs should be larger than that of the two original models. This discovery coincides with the real condition of environmental factor in China. 


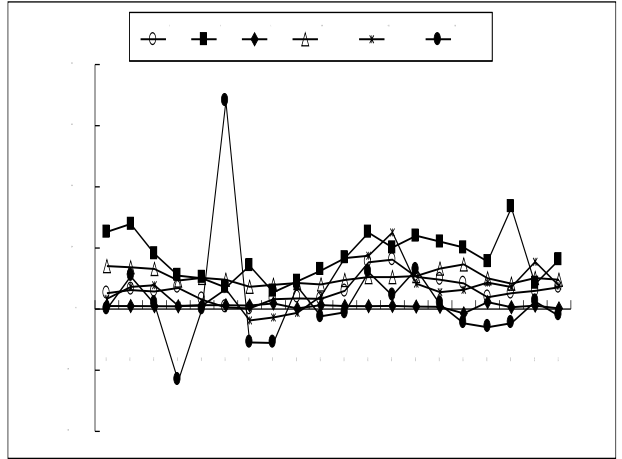

Figure 4. Annual China's inputs and outputs change

Thirdly, actual production activities give priority to economic construction and pay much attention to such policy as energy conservation and emission reduction, so it is obvious that the more desirable outputs and less undesirable outputs are, the better energy efficiency will be. Considering the preference of different outputs, the results of new model should be more accurate than those from BCC and CCR model. For example, in 1997, China was suffered from the effects of Asian financial crisis, under the premise of each investment remaining unchanged, the control of environmental factors are not so ideal, where $\mathrm{SO}_{2}$ emission maximized and $\mathrm{CO}_{2}$ emission reached a recorded height. According to the above analyses, TFEE for 1997 must be low. However, its GDP is still at a growth speed of up to $8.8 \%$ as shown in Figure 4. With the preference of desirable output factor taken into account, the more desirable output, the better the energy efficiency could be, which can explain why 1997's efficiency value reaches a relatively high level at 0.998 . Otherwise, the results must be counterproductive. The situation of 1991 and 1994 are totally opposite to that of 1997, so their efficiency values are at the opposite levels.

In general, along with China's sustained economic growth, the high energy consumption industry and fixed capital investment increased rapidly which will bring resource-conserving and environment-friendly society great challenges. Hence, based on the theoretical and empirical aspects of the research, the analysis results, compared with those from the original CCR and BCC models are more intuitive, comprehensive and accurate, which may provide more accurate scientific foundation for energy and environment policy or strategy making.

\section{Efficiency developing trend analysis}

CCR model enables the overall efficiency to be divided into pure technical efficiency (PTE) and scale efficiency (SE), which offers more adequate information to analyze overall efficiency of inputs producing outputs.

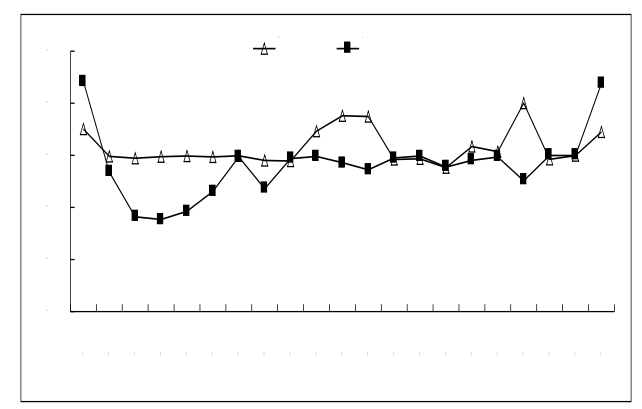

Figure 5. China's pure technical efficiency and scale efficiency, 19912011

PTE reacts to the level of manufacturing management under the existing condition. That is to say, the value of PTE shows the production capacity from the aspect of economic sense. On the other hand, SE is used to judge whether the DMU is in the most appropriate scale or not. When an enterprise is small-scaled, its efficiency must be low. With the process of scale enlargement, the efficiency will reach the maximum value. Meanwhile, if the scale continues to enlarge, then the management may not adapt to the scale, which decreases the efficiency value in the meantime. In other words, the scale efficiency changes in an inverted " $U$ " shape with the change of production process. In order to identify the trend of each kind of efficiency for each year, the trends of China's pure technical efficiency and scale efficiency during 1991 to 2011 are drawn respectively, as shown in Fig. 5.

Generally speaking, it can be referred from Fig. 4 that, the pure technical efficiency value has a slight fluctuation during 1998 to 2011, bottomed out at 0.98 in 2005 and reached the supreme at 1.05 in 2008. Meanwhile, during the period of 1991-2011, the momentum of TFEE has presented a similar fluctuation (Figure 3), which indicates that the growth of PTE is the mainspring in promoting TFEE. As we all know, the degree of opening up has an obvious positive impact on the pure technical efficiency. So it is easy to understand the trend of curve and know the fact that at least until 2005, the police of opening up had been ignored. Typically, there are 3 phases. (i) From 1991 to 2001, China was still in the early and exploring stage of reform and opening up. The advanced technology affected the behindhand production activities strongly. Specifically, PTE value in 2001 reached an unprecedented high, as is shown in Figure 5. (ii) Under the background of globalization, China had been integrated with word market gradually. The way of production, labor productivity and management level had all been improved significantly, which weakens the influence of the advanced technology. What's more, it appeared the phenomenon of "technical rebound" in some coastal developed areas, which may explain the decreasing tendency of PTE from 2001 to 2005. (iii) In recent years, the government has taken such steps as valuing the volume adjustment, eliminating the backward equipment and facilities, compressing the capacity of excess production and shutting down small thermal power units, etc. And these have improved PTE to a certain extent. 
From Fig. 5, scale efficiency in China can be concluded as follow. (i) During 1991-2006, China's SE value decreased from 1.071 to 0.938 gradually. (ii) From 1993 to 2006 the scale efficiency is relatively stable. (iii) It plummeted from 2006 to 2008 and bottomed out at .0976 in 2008. (iv) Rebound was found in 2009, and the scale efficiency was going up during 2009-2011 at a rather high accelerating rate. Compared with the total factor energy efficiency showed in Figure 1, it is not difficult to find that the stableness of TFEE from 1993-2006 and the increasing from 2009 to 2011 were mainly contributed by the well control of the investment scale. So from this aspect, the discussion about scale efficiency is necessary. From 1991 to 1995, the increment of both inputs and outputs had a decreasing trend (Fig. 4), leading to progressively diminishing of SE. This situation reflected the fact that the current phase had a great yield potential, but the shortage of investment affected the outputs, which brings about the decreasing of TFEE. From this point of view, an effective way to improve TFEE was to expand the production scale reasonably. Instead of blindly increasing the resource usage, only the size of production scale was adapted to current management level and technical conditions, could we take full advantage of SE to improve TFEE. Otherwise, the results can only be counterproductive. These may explain the improvement of SE and TFEE from 2002 to 2007.

\section{INFLUENCE FACTORS OF TFEE BASED ON TOBIT REGRESSION}

\section{A. Descriptive statistics of indexes}

The relative efficiency of DMUs had already been evaluated by the new model, and advices can also be put forward for the improvement of the efficiency. However, the factors restricting the total factor energy efficiency are not found. One available approach to accomplish this purpose is to explore the possible affecting factors. So Tobit model could be considered to explore the influence factors. The TFEE system is complex, as shown in Fig. 6.

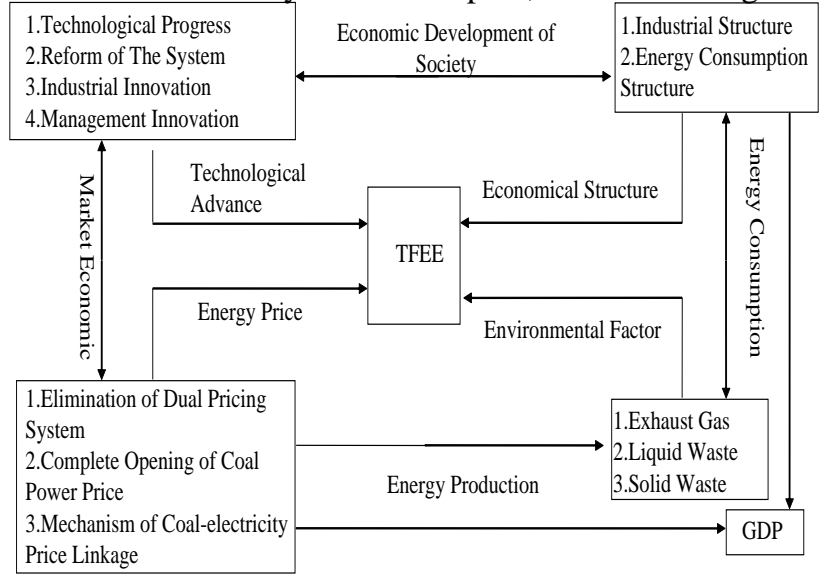

Figure 6. Some main factors of the TFEE system.

Based on the review of related works in the previous researches [15-16], the available data, the existing theory and literature, we take the industrial structure, technological progress, energy price and the environmental factor into account. The variable, sign and the definition are below in Table 3 .
TABLE III. VARIABLE, SIGN AND DEFINITION ABOUT TOBIT ESTIMATE OF ENERGY EFFICIENCY DETERMINANTS

\begin{tabular}{lcl}
\hline Variable & Sign & \multicolumn{1}{c}{ Definition } \\
\hline Industrial Structure & SI & The proportion of secondary industry's outputs in GDP. \\
Technological.Progress & EI & Energy Intensity \\
Energy Price & PE & Purchasing price indices for raw materials, fuels and power. \\
EnvironmentalFactor & EF & $\begin{array}{l}\text { The proportion of investment in the treatment of environmental } \\
\text { pollution in GDP }\end{array}$ \\
& & .
\end{tabular}

The Tobit regression model is defined as follows:

$T F E E_{i}=\beta_{0}+\beta_{1} S I_{i}+\beta_{2} E I_{i}+\beta_{3} P E_{i}+\beta_{4} E F_{i}+\mu_{i}$

Where $\beta_{0}$ is the regression constant, $\beta_{1}-\beta_{4}$ are the independent variable regression coefficients, $i$ is the DMU number, $\mu_{i}$ is the regression error, TFEE is the dependent variable which stands for total factor energy efficiency.

\section{B. Parameter estimation and analysis of regression}

The proposed DEA model is used for the estimation of TFEE values from 1991 to 2011 in China. A Tobit regression analysis is made on the efficiency and defined as the dependent variable, when the industrial structure, technological progress, energy price and the environmental factor are defined as the explanatory variables. The results are listed in Table 4 and 5.

TABLE IV. FACTORS THAT INFLUENCE THE TOTAL FACTOR ENERGY EFFICIENCY OF CHINA

\begin{tabular}{lllll}
\hline & Coefficient & Std. Error & Z-Statistic & Prob. \\
\hline EF & 0.146306 & $2.93 \mathrm{E}-05$ & 1.871710 & 0.0612 \\
$\mathrm{EI}$ & 0.005832 & 0.002458 & 2.372905 & 0.0176 \\
$\mathrm{PE}$ & 0.001097 & 0.000461 & 2.377789 & 0.0174 \\
$\mathrm{SI}$ & -1.166540 & 0.875012 & -2.924820 & 0.0034 \\
$\mathrm{C}$ & 1.805299 & 0.410551 & 4.397256 & 0.0000 \\
\hline
\end{tabular}

TABLE V. ERROR DISTRIBUTION

\begin{tabular}{ccccc}
\hline SCALE:C(6) & 0.049266 & 0.7602 & 6.480743 & 0.0000 \\
\hline Mean dependent var & 0.969705 & S.D. dependent var & 0.065811 \\
Akaike info criterion & -2.611726 & Sum squared resid & 0.050970 \\
Schwarz criterion & -2.313291 & Log likelihood & 33.42313 \\
Hannan-Quinn criter & -2.546958 & Avg. log likelihood & 1.591577 \\
Left censored obs & 0 & Right censored obs & 0 \\
Uncensored obs & 21 & Total obs & 21 \\
\hline
\end{tabular}

Depending on the Tobit regression result above, we explore the impacts on the environmental efficiency in China.

(1) There is a negative and significant correlation between industrial structure and the TFEE. That is, the higher proportion of industrial added value in the GDP, the lower the efficiency is, in agreement with most research results. With other factors unchanged, if the proportion of the industrial production value of the GDP is increased on average by $1 \%$, then the value of total factor energy efficiency decreases by an average of 0.0117 , which could 
be related to the energy-intensive production structure. For a long run, China has been developed in the pattern of "great input, great consumption, great emission but low efficiency". With this extensive mode of production, the situation of heavy industry as the core of China's economic construction may not change in a short time. So high-tech and tertiary industries should be taken as the strategic priorities. Meanwhile, further adjusting the industrial structure should pay much attention to lowering the proportion of energy intensive industries.

(2) Technical progress has a great impact on improving total factor energy efficiency, which advances of every 1 degree will improve the efficiency nearly 0.0058. China has such problems as deficiency of management experience, relatively backward technology, and so on. With the continuously further open of China, a large amount of advanced technology and management systems are pouring into the Chinese market, which alleviates the problems to a large extent. But there still exists some problems, for example, the serious imbalanced technical level between eastern and western areas, the shortage investment of technical progress and unsatisfied R\&D system, etc. Therefore, the government should take the following steps to modify the situation. (i) The backward system will restrain the technical progress, so it is important to perfect the national innovation system, making it efficient, energetic and consistent with the development of market. (ii) China should increase the investment in $\mathrm{R} \& \mathrm{D}$, pay more attention to the selfdependent innovation and further introduction of the strategies abroad o as to raise the overall technical level.

(3) The rising of the relative energy price obviously contributes to the promoting of the total factor energy efficiency, which is consistent with Cheng Jinhua and $\mathrm{Li}$ Shixiang's research [17]. However, compared with the technology progress the rising of the energy price is a little bit weak. Energy price increases 1 unit, and the efficiency will be promoted about 0.0011 . The main reason is that the market-oriented energy price system has imperfections. A large part of the energy product prices can't be able to fully reflect the production cost and the environmental cost. The low energy price has always stimulated the consumption of energy. Particularly, in areas with rich energy resources, local enterprises often use energy to replace the capital investment and labor. Fundamentally, in order to improve TFEE through energy price aspect, the following 2 advice might be available. (i) The government needs to reasonably increase energy price to stimulate the use of energy saving technology, and increase the substitution effect of energy. (ii) From the aspect of system, as in the long run, China has to establish and perfect the reasonable energy price system, set up a link between energy market and energy prices, and change the way the price mechanism is difficult to play a regular role.

(4) For the sack of constructing an environment friendly society, China has a desperate need for energy saving and less pollution emission. Energy production and usage will produce pollution inevitably, so the investment on pollution treatment must be related to the improvement of TFEE. And how great its influence is? The positive correlation coefficient between the environment factor and efficiency is as much as 0.1463 , meaning that if the proportion of investment on pollution treatment in GDP increases 1 unit, then the efficiency will be promoted about 0.1463 . That is to say the environment protection does contribute to the improvement of the TFEE. Therefore, on one hand, the government should further increase investment on pollution treatment. On the other hand, during whole process of energy developing, processing and transportation, we should give priority to those kinds of energy with better economic benefit and light pollution. In short, environment is the basis of all social activities, if it is still blind on the way of market-oriented economic development, then it might result in some environment problems. For example, the releasing of large greenhouse gases emission might change the climate; the pollution of waste water leads more and more people can't access to clean drinking water; the solid waste can pollute the groundwater and ruin the balance of environment, etc. Thus, it is urgent for the government to strengthen the administration and play an efficient role in reducing the environmental pollution emission.

\section{CONCLUSION}

This paper proposes a new measure and describes its characterizations theoretically. Within a joint production framework of desirable output and undesirable outputs, as well as energy input and non-energy inputs, the improved DEA model is developed to evaluate the total factor energy and environmental efficiency of China from 1991 to 2011. The results show that China's energy efficiency has experienced such a trend as "down - rise - stationary wave - rise". Compared with the two original models, the results of the new model are much more consistent with the real change trend in China, which also indicates that the accuracy of the new DEA model is improved. The empirical results also show that the low energy and environmental efficiency of the whole country may be caused by the economic development mode of China. However, effective energy and environmental protection policies implemented by the Chinese government may have resulted from a lot in the improvement of Chinese energy and environmental efficiency.

\section{ACKNOWLEDGMENT}

The relevant researches done in this paper are supported by Natural Social Science Foundation of China (12AZD102), Natural Science Foundation of China (No. 71363046, No.71301064), the Humanistic and Social Science Youth Foundation of Ministry of Education of China (No. 13 YJC790198), the Humanistic and Social Science Foundation of Ministry of Education of China (No. 10YJA790174), Humanistic and Social Science Foundation of Shandong Province (No. 14-ZZ-JG-10), China Federation of Logistics \& Purchasing (2015 CSLKT3 -169), and 2015 Scientific Research Base Innovation Fund Project of Nanjing University of Aeronautics and Astronautics.

\section{REFERENCES}

[1] A. Charnes, W.W. Cooper, E. Rhodes. "Measuring the efficiency of the decision making units", European Journal of Operational Research, pp. 429-444, Feburary, 1978.

[2] Wang QW , Zhou DQ, Ge ShL, Zhou P . "Research on inputoutput efficiency and regulatory cost under environmental 
regulation”. Journal of Management Science. PP.111-119, vol. 22, 2009.

[3] Song ML, Cao XF, Wu J. "A new Non-radial and Bi-objective $D E A$ Model Considering Undesirable Outputs", Journal of Management Science. PP.113-120, Vol. 24, 2011.

[4] S. Reinhard, C.A.K. Lovell, G.J. Thijssen. "Environmental efficiency with multiple environmentally detrimental variables: estimated with SAF and DEA", European Journal of Operational Research. PP. 287-303, vol. 121, 2000.

[5] Wang B, Zhang Q, Wang F. "Using DEA to evaluate firm productive efficiency with environmental performance". Control and Decision. PP. 24-28, vol. 17, 2002.

[6] Wu J, Yang F, Liang L. "A modified complete ranking of DMUs using restrictions in DEA models", Applied Mathematics and Computation. PP.745-751, vol. 217, 2010.

[7] Chen Y. "Measuring super-efficiency in DEA in the presence of infeasibility". European Journal of Operational Research. PP. 447468, vol. 161, 2005.

[8] Bian YW, Yang F. "Resource and environment efficiency analysis of provinces in China: a DEA approach based on Shannon's entropy", Energy Policy. PP. 1909-1917, vol. 38, 2010.

[9] M. Khodabakhshi. "A super-efficiency model based on improved outputs in data envelopment analysis". Applied Mathematics and Computation. PP. 695-703, vol. 184, 2007.

[10] Hu JL, Wang SC. "Total-factor energy efficiency of regions in China", Energy Policy. PP. 3206-3217, vol. 34, 2006.
[11] Ma HL, Huang DH, Yao HZ. "Total-factor Energy Efficiency Analysis of Three Major Economic Regions in China: Based on Super- DEA and Malmquist". China Population (Resources and Environment. PP. 38-43, vol. 21, 2011.

[12] Wang K, Yu SW, Zhang W. "China's regional energy and environmental efficiency: A $D E A$ window analysis based dynamic evaluation". Mathematical and Computer Modelling. (2012), doi:10.1016/j.mcm.2011.11.067.

[13] CSY. China Statistical Yearbook. China Statistical Publishing House, Beijing. 2012.

[14] CESY. China Energy Statistical Yearbook. China Statistical Publishing House, Beijing 1991- 1996, 1997-1999, 2000-2002, 2003, 2004. 2005, 2006, 2007, 2008, 2009, 2010, 2011, 2012.

[15] Shen Zuiyi. "Scale Efficiency of Energy Production in China Based on DEA analysis", Management Science and Statistical Decision.PP. 77-88, vol. 4, 2008.

[16] Huang Dechun, Dong Yuyi, Zhang Changzheng, and Liu Bingsheng. "Regional Energy Efficiency in China Based on a Three-Stage DEA Model". Journal of Resources and Ecology. PP. 97-104, vol. 2, 2014.

[17] Cheng JH, Li ShiX. "Structural shift, technological progress, energy price and energy efficiency". China Population, Resources and Environment . PP. 35-42, vol. 4, 2010. 